\title{
Development and Validation of a Nomogram
}

\section{Predicting the Prognosis of Renal Cell Carcinoma After Nephrectomy}

This article was published in the following Dove Press journal:

Cancer Management and Research

\author{
Mancheng Xia' \\ Haosen Yang ${ }^{2}$ \\ Yusheng Wang' \\ Keqiang Yin' \\ Xiaodong Bian' \\ Jiawei Chen' \\ Weibing Shuang $\mathbb{D}^{3}$ \\ 'First Clinical Medical College, Shanxi \\ Medical University, Taiyuan, People's \\ Republic of China; ${ }^{2}$ Kidney \\ Transplantation Center, Shanxi Second \\ People's Hospital, Taiyuan, People's \\ Republic of China; ${ }^{3}$ Department of \\ Urology, The First Hospital of Shanxi \\ Medical University, Taiyuan, People's \\ Republic of China
}

Objective: To develop and validate a nomogram for predicting the overall survival (OS) of renal cell carcinoma (RCC) patients after nephrectomy.

Materials and Methods: In total, 488 patients with RCC who underwent nephrectomy at the Urology Department of the First Hospital of Shanxi Medical University between January 2013 and December 2018 were randomly divided into a development cohort $(\mathrm{n}=$ $344)$ and a validation cohort $(n=144)$. The development cohort was used to build a prediction model, and the validation cohort was used for validation. Single-factor and multifactor analyses were carried out with $\mathrm{R}$ software, and the nomogram, calibration chart, ROC curve and $\mathrm{C}$ index were constructed.

Results: The median follow-up time of the development and validation cohorts was 34 months. The total 3-year and 5-year survival rates of the development cohort were $93.3 \%$ and $91.6 \%$, respectively; those of the validation cohort were $92.4 \%$ and $91.0 \%$, respectively. Cox univariate analysis of the development cohort showed that age, type 2 diabetes mellitus (T2DM), smoking history, type of surgery, T stage, $\mathrm{N}$ stage, $\mathrm{M}$ stage and Fuhrman nuclear grade were prognostic factors for OS in RCC patients undergoing nephrectomy. Cox multivariate analysis showed that T2DM, smoking history and $\mathrm{T}$ stage were independent prognostic factors for OS in RCC patients undergoing nephrectomy $(\mathrm{P}<0.05)$. According to the univariate and multivariate analyses, a nomogram was constructed. In the development cohort, the $\mathrm{C}$ index of predicted OS was 0.875 (95\% CI, 0.820-0.930). The calibration curve of the 3-year and 5-year survival rates showed that the predicted value of the nomogram was consistent with the actual observed value. The area under the 3-year and 5-year survival ROC curves was 0.861 and 0.901 , respectively. In the validation cohort, the $\mathrm{C}$ index was 0.880 (95\% CI, 0.778-0.982). The calibration curve of the 3-year and 5-year survival rates showed that the predicted value of the nomogram was consistent with the actual observed value. The area under the 3-year and 5-year survival ROC curves was 0.813 and 0.799 , respectively.

Conclusion: We developed and verified a new and accurate nomogram with available clinicopathological data that can effectively predict the OS of RCC patients after nephrectomy.

Keywords: renal cell carcinoma, prognosis, nomogram, influencing factors

\section{Introduction}

Renal cell carcinoma (RCC) is a common malignant tumor of the urinary system that endangers human health, subsequent to prostate cancer and bladder cancer, accounting for $21.82 \%$ of all malignant tumors of the urinary system and $3-5 \%$ of
Correspondence: Weibing Shuang Hospital of Shanxi Medical University, No. 85, JieFang South Road, Yingze District, Taiyuan 03000I, People's Republic of China

Email shuangweibing@I26.com 
all adult malignant tumors. ${ }^{1,2}$ Although nephrectomy provides a long-term survival opportunity for RCC patients, the long-term effect of surgical treatment is not ideal, with a cancer-specific survival (CSS) rate of $86 \%$ and an overall survival (OS) rate of $75 \%$ in 5 years; the CSS and OS rates in 10 years are $78 \%$ and $41 \%$, respectively. ${ }^{3}$ To better predict the prognosis of RCC patients undergoing nephrectomy and provide timely corresponding interventions, it is not enough to rely on tumor staging alone, and various influencing factors need to be considered, including the Fuhrman nuclear grade, type 2 diabetes mellitus (T2DM), smoking history, BMI, age, sex, histological subtype, and operation type. ${ }^{3-10}$ Therefore, the traditional staging system cannot accurately determine patient prognosis. It is necessary to construct a model with multiple factors to predict the prognosis of patients with RCC undergoing nephrectomy, which will help identify patients with a poor prognosis in the early stage so that additional interventions can be taken to prevent or delay recurrence and prolong the expected survival time.

The nomogram is a reliable statistical model. By incorporating risk factors that may affect the prognosis of cancer patients, a graphical prediction tool is established, and evidence-based, personalized, highly accurate and intuitive risk assessment is provided. In a variety of cancer populations, the prediction accuracy of a nomogram is higher than that of the traditional staging system. ${ }^{11}$ In view of the individual prediction ability of this statistical tool, this study aimed to determine the main risk factors affecting the prognosis of RCC patients undergoing nephrectomy and build a new nomogram based on these factors to provide a reference tool for the individual prognostic evaluation of RCC patients undergoing nephrectomy.

\section{Materials and Methods Study Group}

A total of 512 patients with sporadic unilateral RCC who underwent radical or partial nephrectomy between January 2013 and December 2018 were selected. A total of 488 patients were included in the study after the exclusion of those who received only renal biopsy, those with insufficient follow-up data and those with missing data. This study was approved by the ethics committee of the First Hospital of Shanxi Medical University.

\section{Collection of Clinical Data}

The following clinical and pathological data were collected: age; sex; BMI; history of T2DM, hypertension and cardiovascular disease; smoking history; laterality; type of surgery; surgical approach; histological subtype; TNM stage; and Fuhrman grade. All patients received preoperative auxiliary examinations, including chest computed tomography (CT) or X-ray, urinary ultrasound and $\mathrm{CT}$, as well as laboratory examinations. The histological subtype, pathological stage, and classification were determined postoperatively. The histological subtype was determined according to the World Health Organization (WHO) classification standard in $2004,{ }^{12}$ and tumor stage was determined according to the 2010 United States Cancer Council guidelines. ${ }^{13}$ The Fuhrman nuclear grade was classified according to the Fuhrman nuclear grading system recommended by the WHO in $1997 .{ }^{14}$ In this study, T2DM was diagnosed preoperatively if patients used oral hypoglycemic agents or subcutaneous insulin to control blood glucose levels.

\section{Follow-Up}

All patients included in the current study were followed up postoperatively once every three months in the first two years, once every six months in the second two years, and once every year thereafter until death or withdrawal from the study. The last follow-up time was October 2019 and included a physical examination, a laboratory examination, ultrasound, X-ray and a CT scan. OS was determined from the operation time to the date of the last follow-up or death.

\section{Statistical Methods}

R 3.6.1 (http://www.r-project.org) and SPSS 20.0 (IBM, Inc., Armonk, New York) were used for statistical analysis. A total of 488 patients were randomly divided into the development cohort (344 patients) and the validation cohort (144 patients) by R 3.6.1 (http://www.r-project. org) and the "caret" package. Continuous variables are expressed as the mean \pm standard deviation $(\mathrm{x} \pm \mathrm{s})$. An independent sample $t$-test was used for comparisons between the two groups, and the $\chi^{2}$ test was used for comparisons between the two groups of classified variables $(\mathrm{P}<0.05$ was considered statistically significant). According to R 3.6.1 (http://www.r-project.org) and the RMS software package, the development and validation cohorts were analyzed by univariate and multivariate Cox 
analyses ( $\mathrm{P}<0.05$ was considered statistically significant). Based on the results of the univariate and multivariate Cox analyses, the nomogram model of 3-year and 5-year OS was constructed and validated by using $\mathrm{R}$ packages such as rms, foreign, survival, and survivalROC. The $\mathrm{C}$ index, ROC curve and calibration curve were used to evaluate the prediction accuracy of the nomogram $(\mathrm{P}<0.05$ was considered statistically significant), among which 1000 bootstrap resamples were used to calculate the $\mathrm{C}$ index. ${ }^{15,16}$

\section{Results}

\section{Clinical Characteristics}

A total of 488 patients with RCC undergoing radical or partial nephrectomy were enrolled. The median follow-up time of the development cohort $(n=344)$ and the validation cohort ( $\mathrm{n}=144)$ was 34 months. The average patient age of the development cohort (229 males and 115 females) was $57.72 \pm 10.19$ years. The average patient age of the validation cohort (91 males and 53 females) was $57.41 \pm 10.92$ years (Table 1). The 3-year and 5-year OS rates of the development cohort were 93.3\% (23 patients died) and 91.6\% (29 patients died), respectively. The 3-year and 5-year OS rates of the validation cohort were 92.4\% (11 patients died) and 91.0\% (13 patients died), respectively.

\section{Prognostic Factors in the Development Cohort}

The Cox proportional hazards model was used to analyze the 344 patients in the development cohort. In the univariate analysis, age, T2DM, smoking history, type of surgery, T stage, $\mathrm{N}$ stage, $\mathrm{M}$ stage and Fuhrman nuclear grade were significant risk factors $(\mathrm{P}<0.05)$ for $\mathrm{OS}$ in patients with RCC undergoing nephrectomy (Table 2). The multivariate analysis suggested that T2DM, smoking history and $\mathrm{T}$ stage were independent risk factors $(\mathrm{P}<0.05)$. (Table 2$)$

\section{Establishment and Verification of the Prediction Model}

Based on the results of the univariate and multivariate analyses of the development cohort, the eight significant prognostic risk factors were incorporated into the nomogram (Figure 1), and the estimated survival probability of each time point was obtained by adding the total scores. In the development cohort, the $\mathrm{C}$ index of OS was predicted to be 0.875 (95\% CI, 0.820-0.930). The calibration curves of 3-year and 5-year OS show that the predicted and observed values of the nomogram are consistent (Figures
2 and 3), and the areas under the 3-year and 5-year OS ROC curves were 0.861 and 0.901 , respectively (Figures 4 and 5). In the validation cohort, the $\mathrm{C}$ index of predicted OS was $0.880(95 \% \mathrm{CI}, 0.778-0.982)$, the calibration curve of 3-year and 5-year OS showed that the predicted and observed values were consistent (Figures 6 and 7), and the area under the 3-year and 5-year OS ROC curves was 0.813 and 0.799 , respectively (Figures 8 and 9). According to the risk score, we divided the development and validation cohorts into a high-risk group and a low-risk group and compared the OS of the two groups in the two cohorts; the differences were statistically significant $(\mathrm{P}<0.05)$ (Figures 10 and 11).

\section{Discussion}

RCC is the third most common tumor of the urinary system that endangers human health. ${ }^{1,2}$ It exhibits relatively low malignant potential and slow growth. Usually, until the tumor is large enough, there are no early clinical symptoms. ${ }^{17}$ As a malignant disease, RCC continues to threaten human life and health. Although early diagnosis is related to a high cure rate, many patients are in the middle or late stage when they are diagnosed; at this time, the mortality and recurrence rates are high. ${ }^{18}$ Therefore, it is necessary to evaluate the prognosis of RCC patients receiving nephrectomy to provide corresponding intervention measures as early as possible and more accurate treatment guidelines and follow-up management strategies. Nomograms are a kind of visual medical prediction model that have potential clinical application value. They are based on prognostic factors that affect survival. Nomograms can provide accurate, personalized and intuitive predictions for the evaluation of OS.

In recent years, it has been reported that the survival and prognosis of RCC patients undergoing nephrectomy are affected by many factors, such as T stage, Fuhrman nuclear grade, T2DM, smoking history, BMI, age, type of surgery, symptoms, sex, tumor size, and positive lymph nodes. ${ }^{3-10,19,20}$ In addition, Bandini et $\mathrm{al}^{21}$ found that N1 is an independent risk factor for cancer-specific mortality (CSM) of non-metastatic renal cell carcinoma (nmRCC) undergoing nephrectomy. Marchioni et $\mathrm{al}^{22}$ found that the number of positive lymph nodes increased CSM in nmRCC patients with pT3 treated with radical nephrectomy, but did not increase CSM in patients with pT2. These results suggest that we should take the positive lymph nodes and the number of positive lymph nodes into account when evaluating the prognosis of patients 
Table I Patient Characteristics in the Development and Validation Cohorts

\begin{tabular}{|c|c|c|c|c|}
\hline Variables & Overall $(n=488)$ & Development Cohort $(n=344)$ & Validation Cohort $(n=144)$ & P-value \\
\hline Age (y) & $57.63 \pm 10.40$ & $57.72 \pm 10.19$ & $57.4 I \pm 10.92$ & 0.213 \\
\hline Sex & & & & 0.474 \\
\hline Male & 320 & 229 & 91 & \\
\hline Female & 168 & 115 & 53 & \\
\hline BMI $\left(\mathrm{kg} / \mathrm{m}^{2}\right)$ & $24.5 I \pm 3.24$ & $24.44 \pm 3.05$ & $24.67 \pm 3.64$ & 0.137 \\
\hline T2D & & & & 0.202 \\
\hline No & 406 & 291 & 115 & \\
\hline Yes & 82 & 53 & 29 & \\
\hline Hypertension & & & & 0.843 \\
\hline No & 288 & 204 & 84 & \\
\hline Yes & 200 & 140 & 60 & \\
\hline Cardiovascular_disease & & & & 0.219 \\
\hline No & 438 & 305 & 133 & \\
\hline Yes & 50 & 39 & 11 & \\
\hline Smoker & & & & 0.184 \\
\hline No & 356 & 245 & III & \\
\hline Yes & 132 & 99 & 33 & \\
\hline Laterality & & & & 0.886 \\
\hline Left & 228 & 160 & 68 & \\
\hline Right & 260 & 184 & 76 & \\
\hline Type_of_surgery & & & & 0.607 \\
\hline Partial nephrectomy & 147 & 106 & 41 & \\
\hline Radical nephrectomy & 341 & 238 & 103 & \\
\hline Surgical_approach & & & & 0.114 \\
\hline Open nephrectomy & 392 & 270 & 122 & \\
\hline Laparoscopic nephrectomy & 96 & 74 & 22 & \\
\hline Histological_subtype & & & & 0.628 \\
\hline Clear & 442 & 313 & 129 & \\
\hline Unclear & 46 & 31 & 15 & \\
\hline T_stage & & & & 0.416 \\
\hline Tla & 272 & 190 & 82 & \\
\hline TIb & 146 & 106 & 40 & \\
\hline $\mathrm{T} 2$ & 44 & 33 & 11 & \\
\hline T3-4 & 26 & 15 & 11 & \\
\hline N_stage & & & & 0.707 \\
\hline No & 474 & 333 & $|4|$ & \\
\hline $\mathrm{NI}$ & 14 & 11 & 3 & \\
\hline M_stage & & & & $0.45 I$ \\
\hline Mo & 457 & 324 & 133 & \\
\hline MI & 31 & 20 & 11 & \\
\hline Fuhrman_grade & & & & 0.18 \\
\hline GI-G2 & 413 & 296 & 117 & \\
\hline G3-G4 & 75 & 48 & 27 & \\
\hline
\end{tabular}

Abbreviations: BMI, body mass index; T2D, type 2 diabetes. 
Table 2 Univariable and Multivariable Cox Regression Models for Predicting OS in the Development and Validation Cohorts

\begin{tabular}{|c|c|c|c|c|c|c|c|c|}
\hline \multirow[t]{3}{*}{ Variables } & \multicolumn{4}{|c|}{ Development Cohort $(n=344)$} & \multicolumn{4}{|c|}{ Validation Cohort $(n=144)$} \\
\hline & \multicolumn{2}{|l|}{ Univariable } & \multicolumn{2}{|l|}{ Multivariable } & \multicolumn{2}{|l|}{ Univariable } & \multicolumn{2}{|l|}{ Multivariable } \\
\hline & HR (95\% Cl) & P value & HR (95\% Cl) & $P$ value & HR (95\% Cl) & $P$ value & HR (95\% Cl) & $P$ value \\
\hline $\begin{array}{l}\text { Age }(y) \\
\quad<65 \\
\quad \geq 65\end{array}$ & $\begin{array}{l}\text { Reference } \\
2.13 \\
(1.016-4.466)\end{array}$ & 0.045 & $\begin{array}{l}1.333 \\
(0.582-3.05 I)\end{array}$ & 0.496 & $\begin{array}{l}\text { Reference } \\
0.843 \\
(0.232-3.064)\end{array}$ & 0.795 & & \\
\hline $\begin{array}{l}\text { Sex } \\
\qquad \text { Male } \\
\text { Female }\end{array}$ & $\begin{array}{l}\text { Reference } \\
0.63 \\
(0.269-1.474)\end{array}$ & 0.287 & & & $\begin{array}{l}\text { Reference } \\
0.144 \\
(0.019-1.107)\end{array}$ & 0.063 & & \\
\hline $\begin{array}{l}\text { BMl }(\mathrm{kg} / \mathrm{m} 2) \\
\quad<25 \\
\quad \geq 25\end{array}$ & $\begin{array}{l}\text { Reference } \\
1.527 \\
(0.735-3.173)\end{array}$ & 0.256 & & & $\begin{array}{l}\text { Reference } \\
2.021 \\
(0.661-6.18)\end{array}$ & 0.217 & & \\
\hline $\begin{array}{l}\text { T2D } \\
\text { No } \\
\text { Yes }\end{array}$ & $\begin{array}{l}\text { Reference } \\
4.543 \\
(2.164-9.537)\end{array}$ & $<0.001$ & $\begin{array}{l}8.622 \\
(3.240-22.94 I)\end{array}$ & $<0.001$ & $\begin{array}{l}\text { Reference } \\
1.921 \\
(0.59-6.258)\end{array}$ & 0.278 & & \\
\hline $\begin{array}{l}\text { Hypertension } \\
\text { No } \\
\text { Yes }\end{array}$ & $\begin{array}{l}\text { Reference } \\
\mathrm{I} .63 \mathrm{I} \\
(0.787-3.38 \mathrm{I})\end{array}$ & 0.188 & & & $\begin{array}{l}\text { Reference } \\
\text { I.66I } \\
(0.558-4.943)\end{array}$ & 0.362 & & \\
\hline $\begin{array}{l}\text { Cardiovascular_disease } \\
\text { No } \\
\text { Yes }\end{array}$ & $\begin{array}{l}\text { Reference } \\
\text { I.68 } \\
(0.635-4.442)\end{array}$ & 0.296 & & & $\begin{array}{l}\text { Reference } \\
\text { NA }\end{array}$ & 0.998 & & \\
\hline $\begin{array}{l}\text { Smoker } \\
\text { No } \\
\text { Yes }\end{array}$ & $\begin{array}{l}\text { Reference } \\
3.015 \\
(1.447-6.283)\end{array}$ & 0.003 & $\begin{array}{l}2.814 \\
(1.254-6.317)\end{array}$ & 0.012 & $\begin{array}{l}\text { Reference } \\
3.616 \\
(1.209-10.82)\end{array}$ & 0.022 & $\begin{array}{l}2.576 \\
(0.750-8.853)\end{array}$ & 0.133 \\
\hline $\begin{array}{l}\text { Laterality } \\
\text { Left } \\
\text { Right }\end{array}$ & $\begin{array}{l}\text { Reference } \\
0.944 \\
(0.455-1.957)\end{array}$ & 0.877 & & & $\begin{array}{l}\text { Reference } \\
0.796 \\
(0.268-2.37)\end{array}$ & 0.682 & & \\
\hline $\begin{array}{l}\text { Type_of_surgery } \\
\text { Partial nephrectomy } \\
\text { Radical nephrectomy }\end{array}$ & $\begin{array}{l}\text { Reference } \\
3.565 \\
(1.077-11.8)\end{array}$ & 0.037 & $\begin{array}{l}2.318 \\
(0.580-9.263)\end{array}$ & 0.234 & $\begin{array}{l}\text { Reference } \\
1.315 \\
(0.362-4.78)\end{array}$ & 0.678 & & \\
\hline $\begin{array}{l}\text { Surgical_approach } \\
\text { Open nephrectomy } \\
\text { Laparoscopic } \\
\text { nephrectomy }\end{array}$ & $\begin{array}{l}\text { Reference } \\
2.076 \\
(0.98-4.399)\end{array}$ & 0.057 & & & $\begin{array}{l}\text { Reference } \\
0.947 \\
(0.21-4.272)\end{array}$ & 0.943 & & \\
\hline $\begin{array}{l}\text { Histological_subtype } \\
\text { Clear }\end{array}$ & Reference & & & & Reference & & & \\
\hline
\end{tabular}

(Continued) 
Table 2 (Continued).

\begin{tabular}{|c|c|c|c|c|c|c|c|c|}
\hline \multirow[t]{3}{*}{ Variables } & \multicolumn{4}{|c|}{ Development Cohort $(n=344)$} & \multicolumn{4}{|c|}{ Validation Cohort $(n=144)$} \\
\hline & \multicolumn{2}{|l|}{ Univariable } & \multicolumn{2}{|l|}{ Multivariable } & \multicolumn{2}{|l|}{ Univariable } & \multicolumn{2}{|l|}{ Multivariable } \\
\hline & HR $(95 \% \mathrm{Cl})$ & $P$ value & HR (95\% Cl) & $P$ value & HR (95\% Cl) & $P$ value & HR (95\% Cl) & $P$ value \\
\hline Unclear & $\begin{array}{l}1.06 \\
(0.32-3.507)\end{array}$ & 0.924 & & & $\begin{array}{l}3.603 \\
(1.102-11.77)\end{array}$ & 0.034 & $\begin{array}{l}1.815 \\
(0.453-7.270)\end{array}$ & 0.4 \\
\hline T_stage & & & & & & & & \\
\hline Tla & Reference & & & & Reference & & & \\
\hline TIb & $\begin{array}{l}2.043 \\
(0.806-5.183)\end{array}$ & 0.132 & $\begin{array}{l}1.249 \\
(0.422-3.697)\end{array}$ & 0.688 & $\begin{array}{l}0.843 \\
(0.163-4.348)\end{array}$ & 0.838 & $\begin{array}{l}0.957 \\
(0.18 I-5.056)\end{array}$ & 0.958 \\
\hline $\mathrm{T} 2$ & $\begin{array}{l}6.381 \\
(2.331-17.463)\end{array}$ & $<0.001$ & $\begin{array}{l}10.847 \\
(3.1 \mid 8-37.732)\end{array}$ & $<0.001$ & $\begin{array}{l}8.554 \\
(2.286-32.009)\end{array}$ & 0.001 & $\begin{array}{l}3.082 \\
(0.550-17.259)\end{array}$ & 0.2 \\
\hline T3-4 & $\begin{array}{l}6.352 \\
(1.954-20.65)\end{array}$ & 0.002 & $\begin{array}{l}6.133 \\
(1.301-28.738)\end{array}$ & 0.021 & $\begin{array}{l}3.262 \\
(0.631-16.857)\end{array}$ & 0.158 & $\begin{array}{l}1.220 \\
(0.190-7.826)\end{array}$ & 0.834 \\
\hline $\begin{array}{c}\text { N_stage } \\
\text { No } \\
\text { NI }\end{array}$ & $\begin{array}{l}\text { Reference } \\
12.532 \\
(5.024-3 \mid .26)\end{array}$ & $<0.001$ & $\begin{array}{l}2.657 \\
(0.436-16.205)\end{array}$ & 0.289 & $\begin{array}{l}\text { Reference } \\
4.256 \\
(0.553-32.79)\end{array}$ & 0.164 & & \\
\hline $\begin{array}{c}\text { M_stage } \\
\text { MO } \\
\text { MI }\end{array}$ & $\begin{array}{l}\text { Reference } \\
6.677 \\
(2.694-16.55)\end{array}$ & $<0.001$ & $\begin{array}{l}2.124 \\
(0.402-11.210)\end{array}$ & 0.375 & $\begin{array}{l}\text { Reference } \\
6.483 \\
(1.988-21.14)\end{array}$ & $<0.005$ & $\begin{array}{l}3.060 \\
(0.705-13.284)\end{array}$ & 0.136 \\
\hline $\begin{array}{l}\text { Fuhrman_grade } \\
\qquad \begin{array}{l}\text { GI-2 } \\
\text { G3-4 }\end{array}\end{array}$ & $\begin{array}{l}\text { Reference } \\
3.193 \\
(1.452-7.02)\end{array}$ & 0.004 & $\begin{array}{l}2.258 \\
(0.952-5.357)\end{array}$ & 0.064 & $\begin{array}{l}\text { Reference } \\
8.637 \\
(2.819-26.46)\end{array}$ & $<0.001$ & $\begin{array}{l}5.138 \\
(1.355-19.479)\end{array}$ & 0.016 \\
\hline
\end{tabular}

Abbreviations: OS, overall survival; BMI, body mass index; T2D, type 2 diabetes; NA, not available.

with nmRCC after operation. Our study shows that age, T2DM, smoking history, type of surgery, $\mathrm{T}$ stage, $\mathrm{N}$ stage, $\mathrm{M}$ stage and Fuhrman nuclear grade are influential factors in the OS of RCC patients undergoing nephrectomy, which is roughly consistent with previous studies.

Yaycioglu et $\mathrm{al}^{19}$ have shown that age, sex, symptoms, tumor size, the presence of radioactive lymph nodes and clinical stage are prognostic factors of relapse-free survival (RFS) in patients with nmRCC, and all of these factors except for age are independent predictors of RFS in patients with nmRCC. Based on these prognostic factors, a nomogram for predicting RFS after an operation to treat RCC was developed and validated. The $\mathrm{C}$ index of the nomogram is 0.747 . Karakiewicz et $\mathrm{al}^{20}$ analyzed the survival of 2474 patients with RCC undergoing nephrectomy by univariate and multivariate Cox regression analyses. In the univariate analysis, TNM stage, age, sex, symptoms and tumor size were revealed as prognostic factors of CSS in patients with RCC undergoing nephrectomy. In the multivariate analysis, in addition to sex, other factors were also identified as independent prognostic factors. A nomogram was constructed to predict the prognosis of CSS in patients with RCC undergoing nephrectomy. The accuracy was $0.842-0.881$. Raj et $\mathrm{al}^{23}$ constructed a nomogram for predicting RFS after nephrectomy in 2517 patients with RCC. The nomogram included sex, symptoms, lymphadenopathy, signs of tumor necrosis, tumor size and other prognostic factors. The $\mathrm{C}$ index was 0.8 . Our study shows that age, a history of T2DM, smoking history, type of surgery, T stage, $\mathrm{N}$ stage, $\mathrm{M}$ stage and Fuhrman nuclear grade are prognostic factors affecting the OS of patients with RCC after an operation, and T2DM, smoking history and $\mathrm{T}$ stage are independent prognostic factors. Considering that the OS of patients in clinical practice is affected by a variety of clinical pathological 
Points

Age

T2D

Smoker

Type_of_surgery

T_stage

N_stage

M_stage

Fuhrman_grade

Total Points

3-Year Survival

5-Year survival

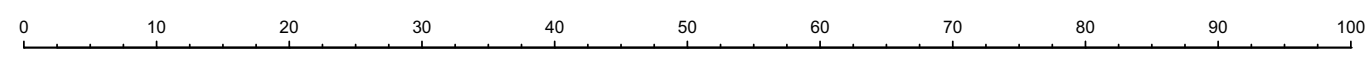

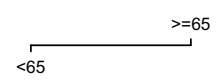

$$
\text { Non-T2D }
$$

T2D

Yes

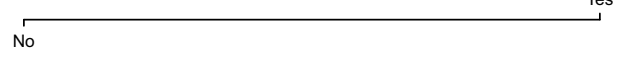

$\mathrm{RN}$
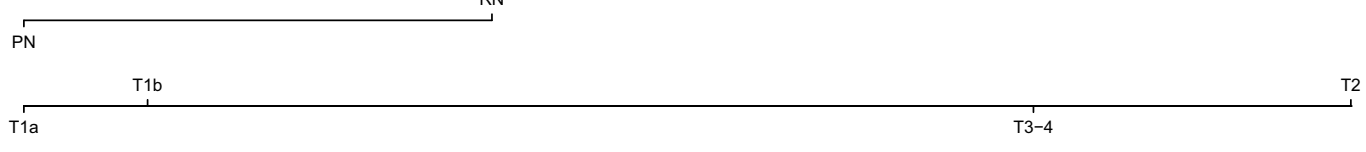

N1

No

M0

M1

$\mathrm{G} 1-2$

G3-4
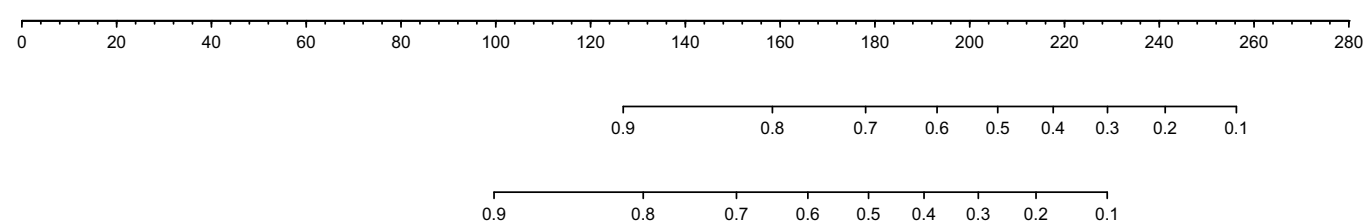

Figure I Nomogram for the prediction of OS in RCC patients after nephrectomy.

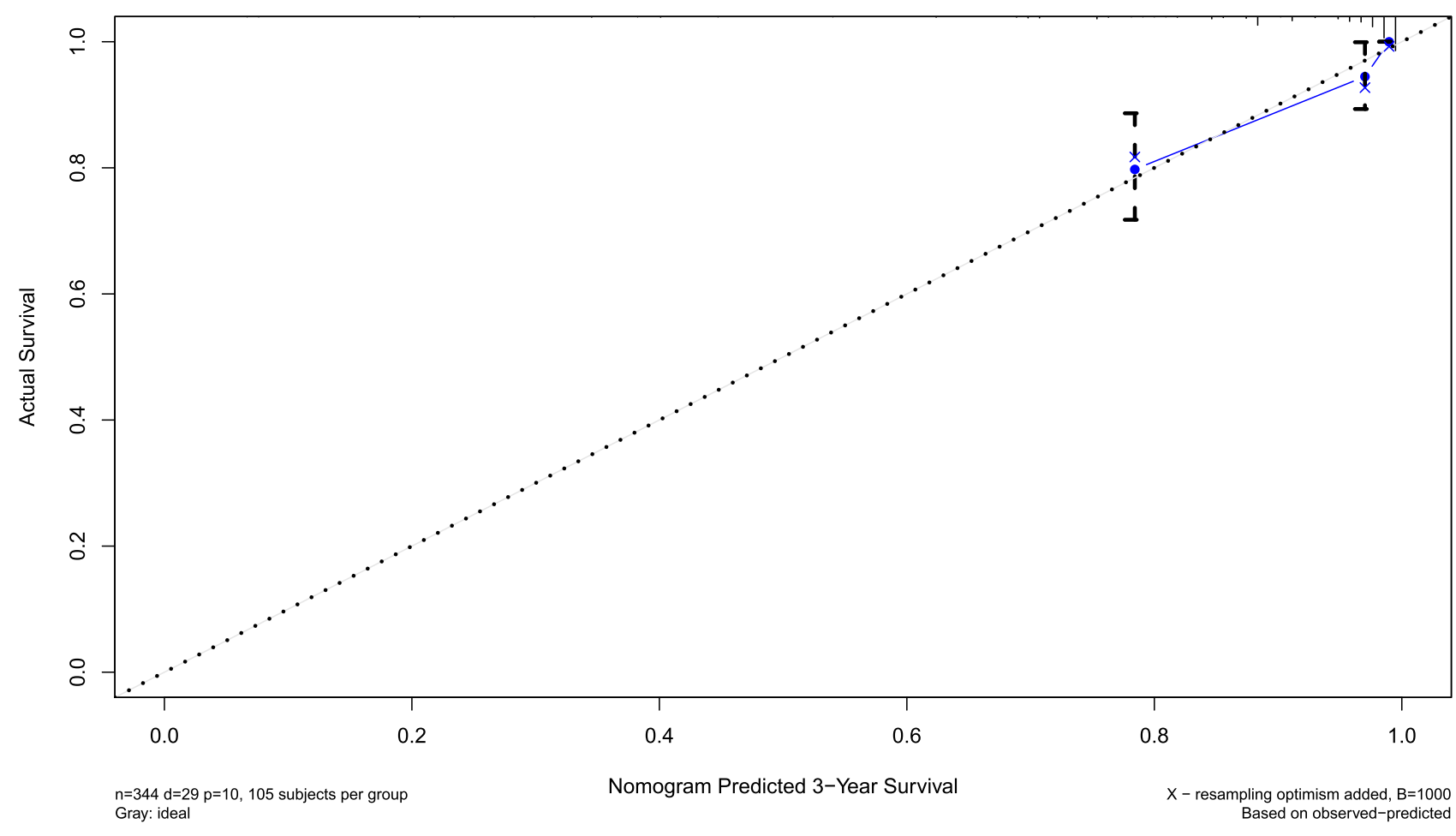

Figure 2 Calibration plot of OS at 3 years in the development cohort. 


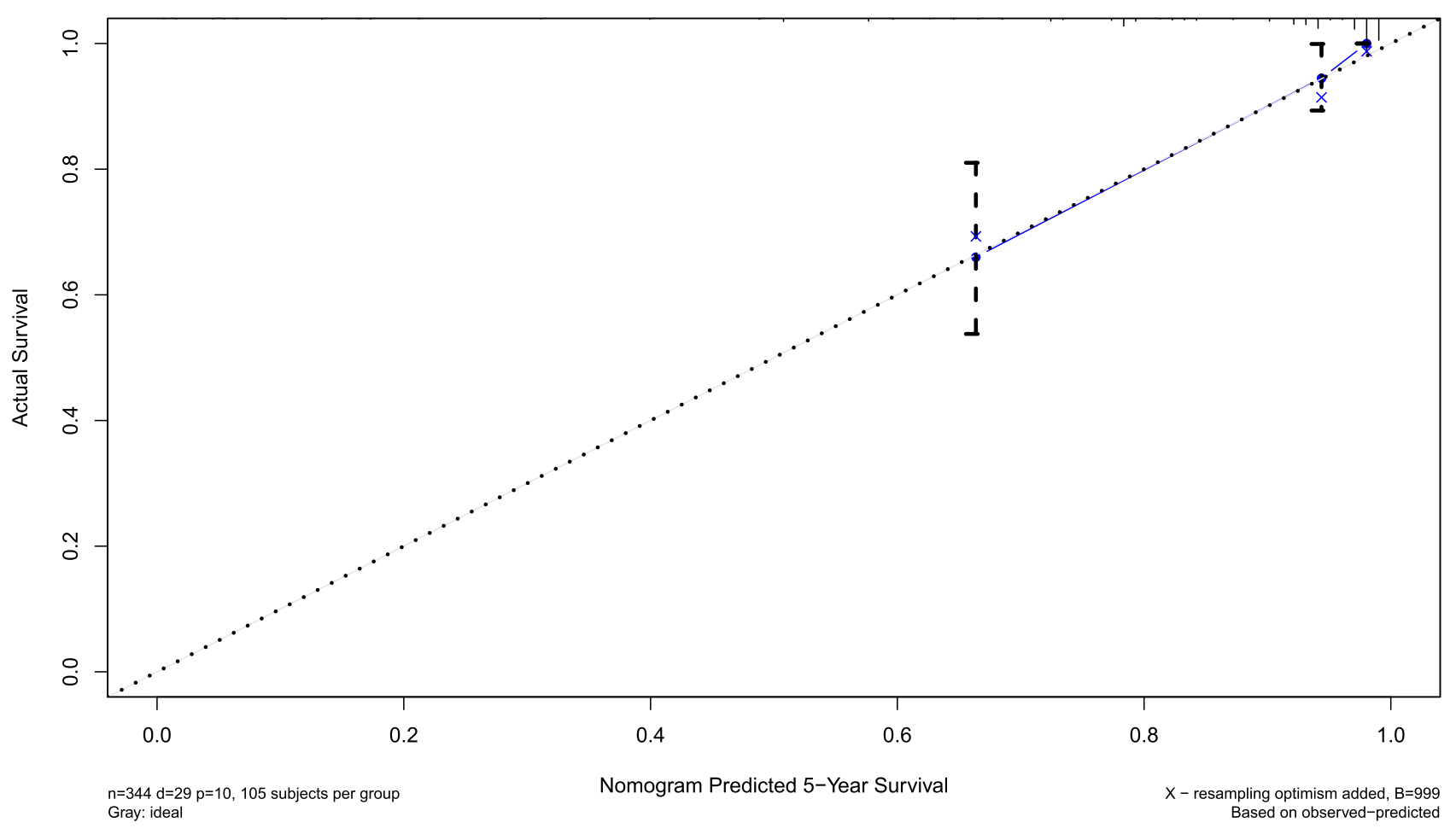

Figure 3 Calibration plot of OS at 5 years in the development cohort.

factors, we included the above eight factors, and the $\mathrm{C}$ index was 0.875 .

The accuracy of our nomogram is significantly higher than that of the two existing models $(0.747-0.8),{ }^{19,23}$ and the accuracy is similar to that of the model described by
Karakiewicz. ${ }^{20}$ In addition to the use of pathological data (eg, Fuhrman grade, T stage), clinical information such as T2DM, smoking history, and surgical methods was also included; these factors were not included in the other three prediction models. It's worth noting that our study shows 3-year Survival AUC $=0.861$

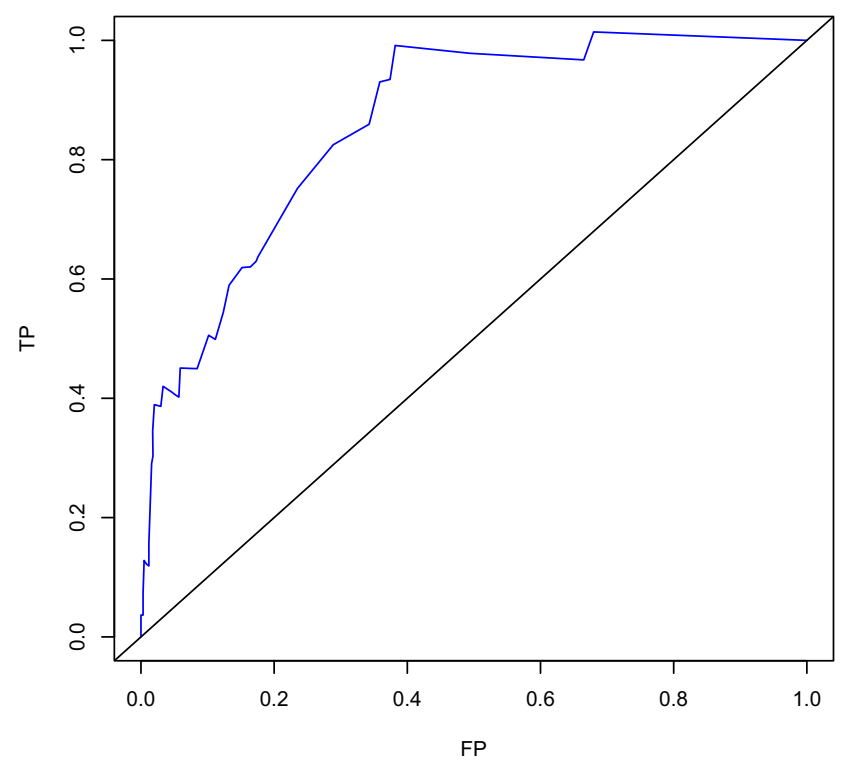

Figure 4 ROC curve of the 3-year OS in the development cohort.

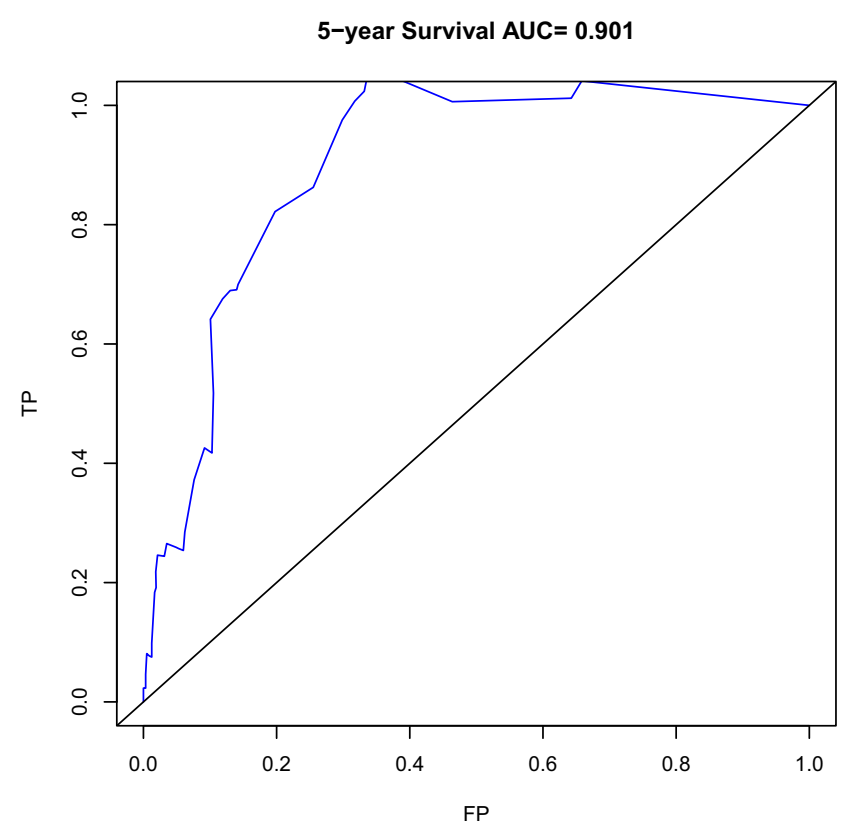

Figure 5 ROC curve of the 5-year OS in the development cohort. 


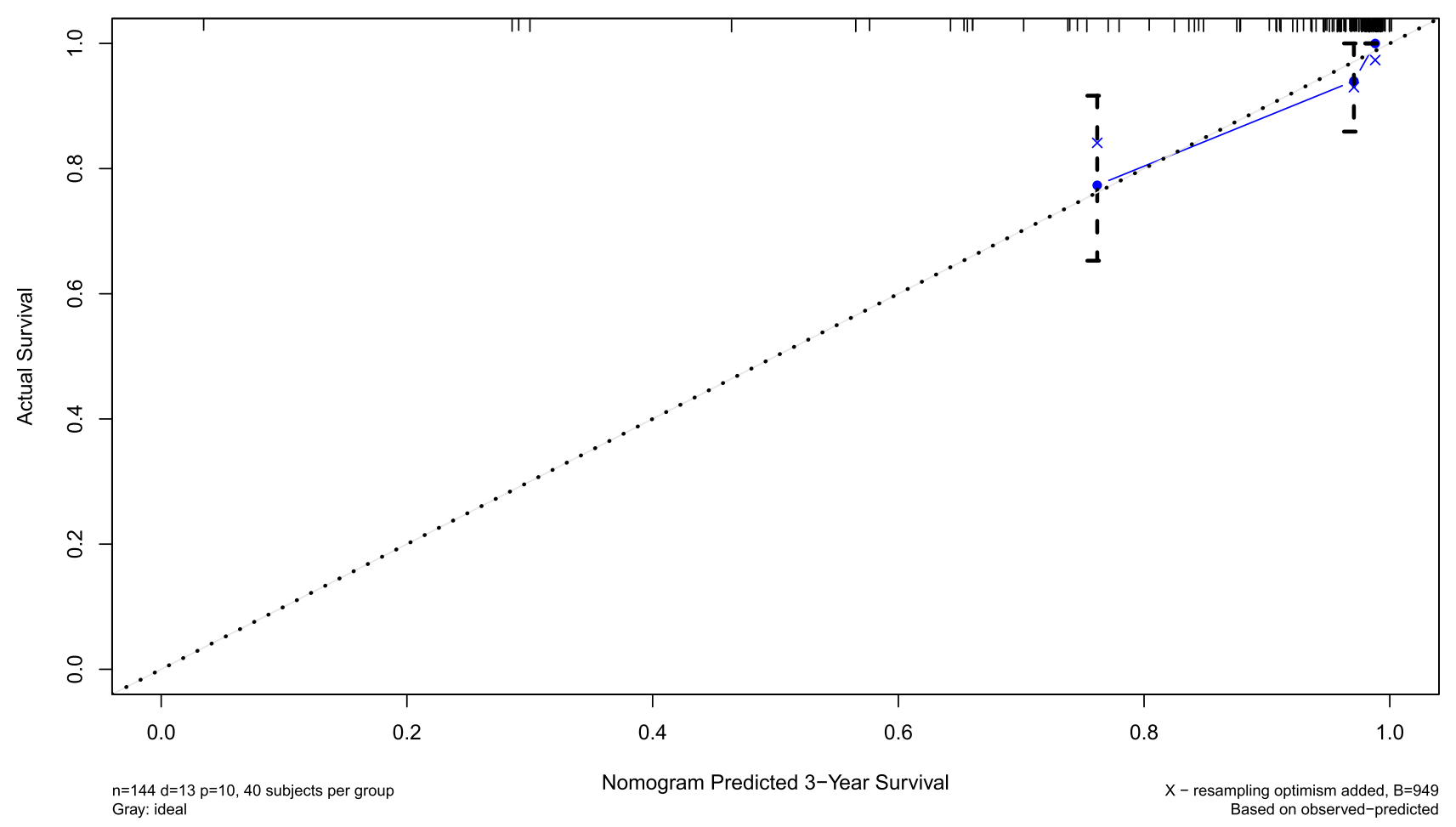

Figure 6 Calibration plot of OS at 3 years in the validation cohort.

that T2DM is an independent risk factor of OS in patients the secretion of insulin-like growth factor-1 (IGF-1) to with RCC undergoing nephrectomy. The mechanism is stimulate cell proliferation. Because high insulin can related to insulin resistance-related hyperinsulinemia and increase the level of IGF-1 to promote the proliferation

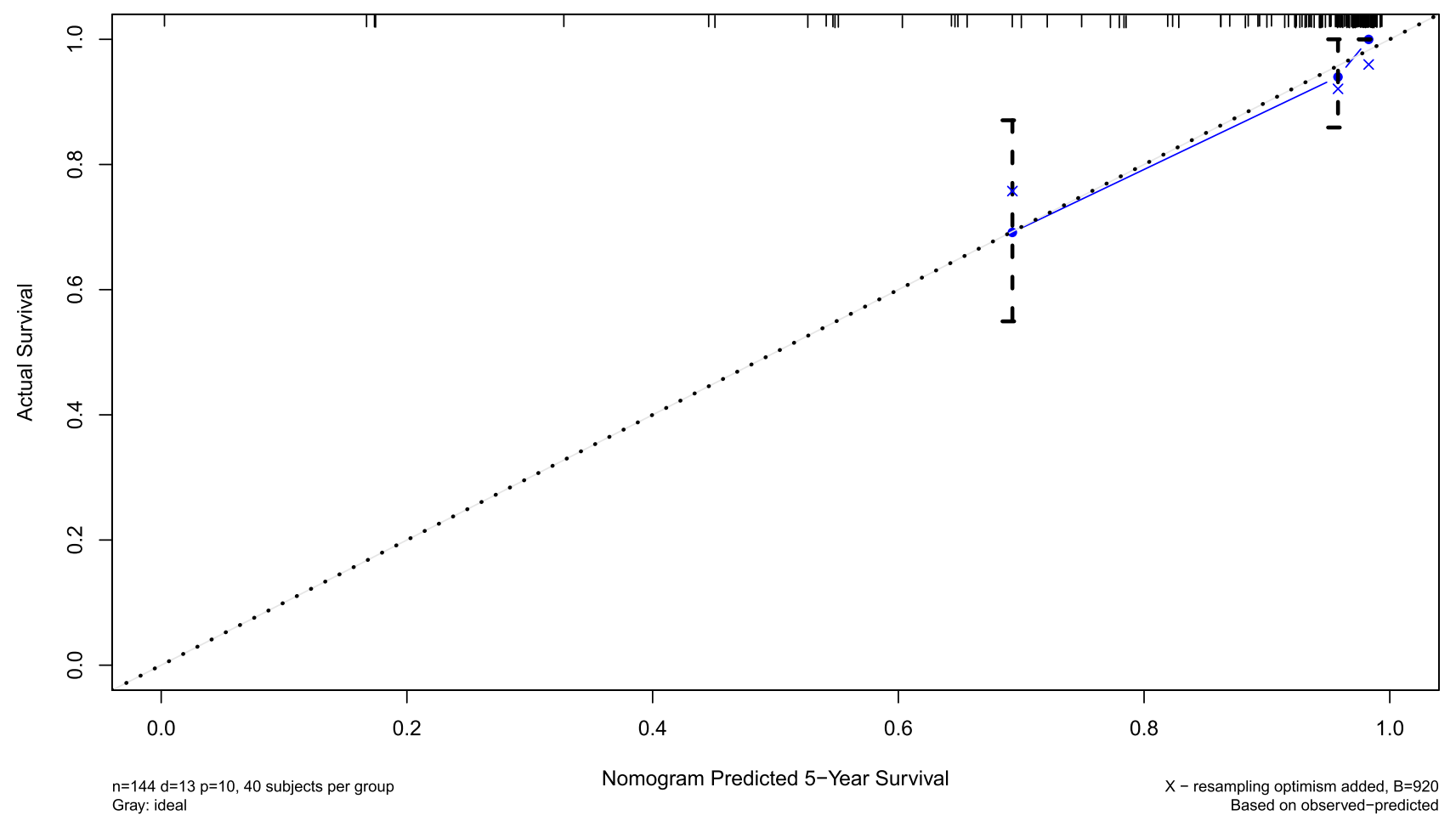

Figure 7 Calibration plot of OS at 5 years in the validation cohort. 
3-year Survival AUC $=0.813$

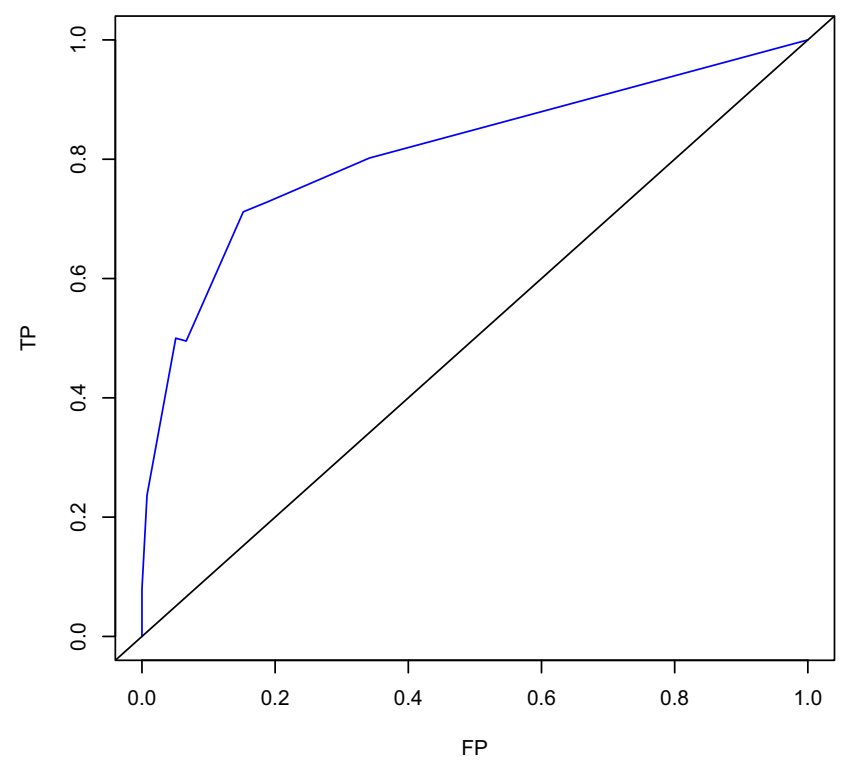

Figure 8 ROC curve of the 3-year OS in the validation cohort.

and differentiation of tumor cells and inhibit apoptosis, thereby accelerating the proliferation of cancer cells. In addition, high levels of insulin and IGF-1 will also increase the secretion of vascular endothelial growth factor (VEGF), up-regulate the expression of VEGF, induce tumor neovascularization, and promote the occurrence and metastasis of tumor, which would lead to poor prognosis of patients with $\mathrm{RCC}^{24-26}$

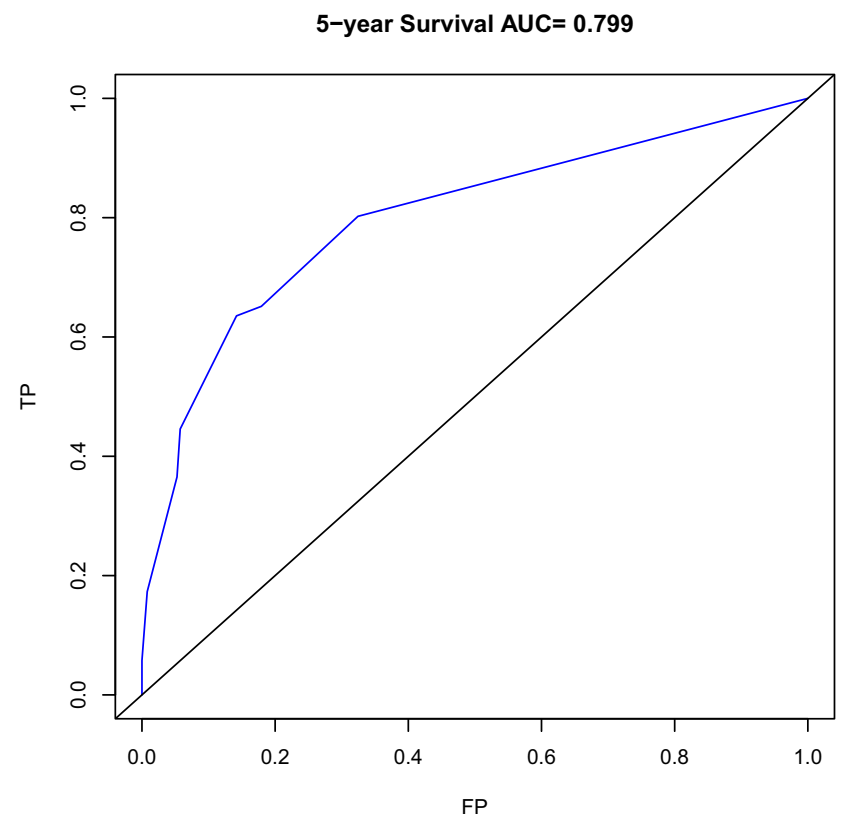

Figure 9 ROC curve of the 5 -year OS in the validation cohort.
Survival curve of risk score $(\mathrm{P}<0.05)$

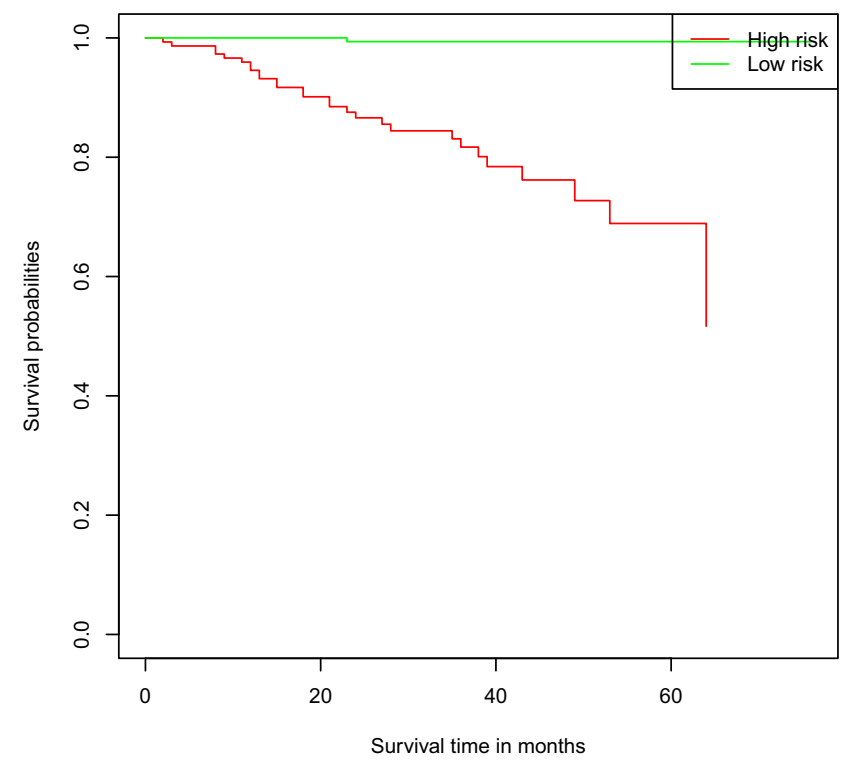

Figure 10 Kaplan-Meier curves of different risk groups stratified by the nomogram in the development cohort $(P<0.05)$.

In recent years, in addition to using a nomogram to develop models for predicting the survival time of RCC patients after an operation, some researchers have also developed models for predicting the OS, CSS, RFS and disease-free survival (DFS) of RCC patients undergoing nephrectomy. ${ }^{27-34}$ Based on the survival rate of RCC patients undergoing nephrectomy, scoring systems were

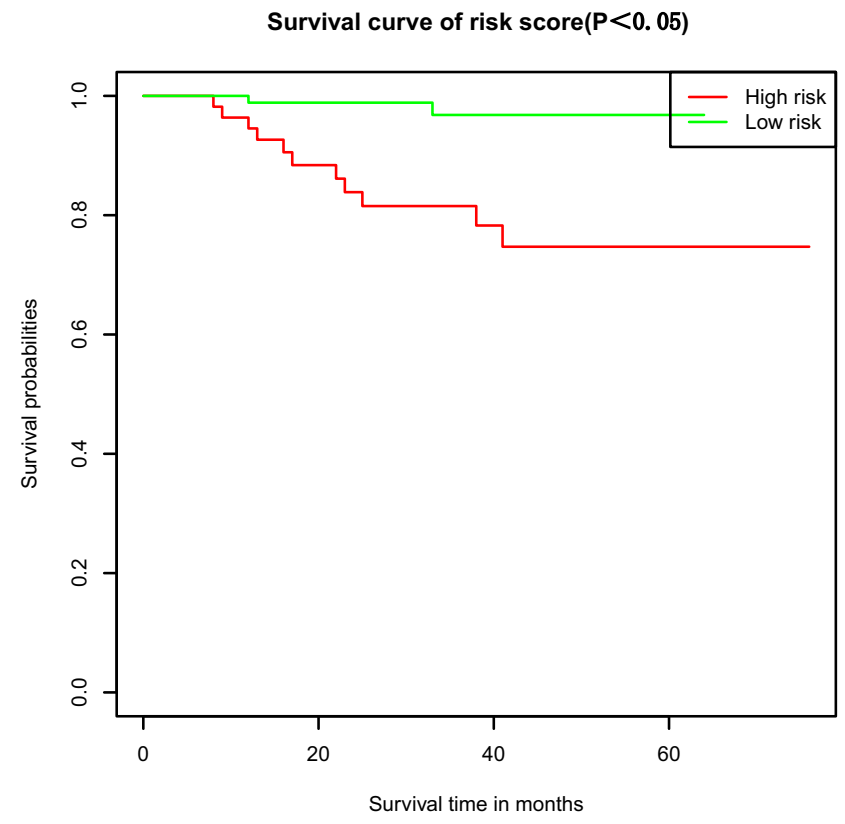

Figure II Kaplan-Meier curves of different risk groups stratified by the nomogram in the validation cohort $(P<0.05)$. 
constructed by prognostic factors, including positive margins, TNM stage, lymph node status, tumor size, Fuhrman nuclear grade, tumor necrosis, age, clinical manifestations, microvascular invasion, preoperative platelet count, neutrophil/lymphocyte ratio, with an accuracy of $0.68-0.86 .^{29,35} \mathrm{Zhu}$ et al divided patients into three risk groups (low-risk group, medium-risk group and high-risk group) according to their scores, which were used to predict the OS, RFS, DFS and CSS of patients after nephrectomy. ${ }^{29,34,36}$ May et $\mathrm{al}^{29}$ also found that when the cut-off value of the tumor size group changed from $7 \mathrm{~cm}$ to $5 \mathrm{~cm}$, its predictive value significantly increased. Zhu et $\mathrm{al}^{36}$ set the best dividing point with the ROC curve so that the model was more accurate. The advantage of these scoring systems is that the calculation is simple and clear, but it is not visual enough. Buti et $\mathrm{al}^{37,38}$ used five risk groups in SEER database to verify GRANT score, which further proved the reliability of GRANT score in RCC prediction.

To some extent, the nomogram developed by us is helpful to find out the RCC patients with poor OS in time to give them more attention and even timely intervention after operation, so as to prolong their OS. Bandini et $\mathrm{al}^{39}$ reviewed the literatures on adjuvant therapy of nmRCC after nephrectomy, and discussed the effect of adjuvant therapy on tumor control. Traditional adjuvant therapy drugs, including INF- $\alpha$, IL-2, autogenous tumor cell vaccines and monoclonal antibodies, had no survival benefit for patients with nmRCC after nephrectomy. However, the effect of targeted therapy is still controversial, so more studies are needed to explore and confirm the benefits of adjuvant therapy in patients with nmRCC after nephrectomy. Ravaud et $\mathrm{al}^{40}$ studied the efficacy and safety of sunitinib in the treatment of local RCC with high recurrence risk after nephrectomy. The median DFS of sunitinib group was significantly longer than that of placebo group, but the incidence of toxic events of sunitinib group was also higher. Therefore, when using sunitinib, we should pay attention to its toxicity. Bex et $\mathrm{al}^{41}$ had shown that immediate cytoreductive nephrectomy should not be considered as the treatment standard for patients with moderate or low-risk metastatic renal cancer when drug treatment is needed. Karakiewicz et $\mathrm{al}^{42}$ showed that for high-risk nmRCC, it is not recommended to use TKI based adjuvant therapy after nephrectomy, but patients with high enthusiasm can benefit from discussing the risks and benefits of adjuvant TKI with tumor experts. It can be seen that the effect of adjuvant therapy after nephrectomy for RCC is still controversial, and more research is needed.

The nomogram developed by us has the advantages of accuracy, individuation and intuitionism. At least in Shanxi Province of China, it has good promotion potential. Its limitation lies in the use of the Fuhrman grade, which is ineffective for a rare histology, and the TNM stage will be modified over time. In addition, because this study is a single-center retrospective study, potential selection bias is inevitable; therefore, more multicenter, prospective studies are needed for further verification. Second, the sample size of this study is relatively small, and few risk factors were included in the model. Therefore, it is necessary to further expand the sample size and incorporate more recognized prediction factors into future validation studies to improve the performance of the model.

\section{Conclusions}

In conclusion, a new nomogram established by the author can effectively predict the OS of RCC patients undergoing nephrectomy, and the validation results show that the nomogram has an accurate prediction performance. According to relevant prognostic factors, RCC patients undergoing nephrectomy can be divided into low-risk and high-risk groups to provide a certain reference value for the prognostic evaluation of RCC patients after nephrectomy.

\section{Ethics Statement}

This study was reviewed and approved by the ethics committee of the First Hospital of Shanxi Medical University as a retrospective study. This study was conducted in accordance with the Declaration of Helsinki. Due to the retrospective nature of this study, the requirement for patient-informed consent was waived and the confidentiality of patients' data was protected.

\section{Acknowledgments}

We thank all the participants involved in this study.

\section{Author Contributions}

All authors contributed to data analysis, drafting or revising the article, gave final approval of the version to be published, and agree to be accountable for all aspects of the work.

\section{Disclosure}

All authors declare no conflicts of interest. 


\section{References}

1. Siegel RL, Miller KD, Jemal A. Cancer statistics, 2019. CA Cancer J Clin. 2019;69(1):7-34. doi:10.3322/caac.21551

2. Miller KD, Nogueira L, Mariotto AB, et al. Cancer treatment and survivorship statistics, 2019. CA Cancer J Clin. 2019;69(5):363-385. doi: $10.3322 /$ caac. 21565

3. Borgmann H, Musquera M, Haferkamp A, et al. Prognostic significance of Fuhrman grade and age for cancer-specific and overall survival in patients with papillary renal cell carcinoma: results of an international multi-institutional study on 2189 patients. World J Urol. 2017;35(12):1891-1897. doi:10.1007/s00345-017-2078-5

4. Cumberbatch MG, Rota M, Catto JW, et al. The role of tobacco smoke in bladder and kidney carcinogenesis: a comparison of exposures and meta-analysis of incidence and mortality risks. Eur Urol. 2016;70(3):458-466. doi:10.1016/j.eururo.2015.06.042

5. Kang HW, Seo SP, Kim WT, et al. Impact of young age at diagnosis on survival in patients with surgically treated renal cell carcinoma: a multicenter study. J Korean Med Sci. 2016;31(12):1976-1982. doi:10.3346/jkms.2016.31.12.1976

6. Patel NH, Attwood KM, Hanzly M, et al. Comparative analysis of smoking as a risk factor among renal cell carcinoma histological subtypes. $J$ Urol. 2015;194(3):640-646. doi:10.1016/j. juro.2015.03.125

7. Chen $\mathrm{L}, \mathrm{Li} \mathrm{H}, \mathrm{Gu} \mathrm{L}$, et al. The impact of diabetes mellitus on renal cell carcinoma prognosis: a meta-analysis of cohort studies. Medicine. 2015;94(26):e1055. doi:10.1097/MD.0000000000001055

8. Gati A, Kouidhi S, Marrakchi R, et al. Obesity and renal cancer: role of adipokines in the tumor-immune system conflict. Oncoimmunology. 2014;3(1):e27810. doi:10.4161/onci.27810

9. Ha YS, Kim WT, Yun SJ, et al. Multi-institutional analysis of localized renal cell carcinoma that demonstrates the impact of diabetic status on prognosis after nephrectomy. Ann Surg Oncol. 2013;20 (11):3662-3668. doi:10.1245/s10434-013-3147-7

10. Leslie S, Goh AC, Gill IS. Partial nephrectomy-contemporary indications, techniques and outcomes. Nat Rev Urol. 2013;10 (5):275-283. doi:10.1038/nrurol.2013.69

11. Jeldres C, Sun M, Lughezzani G, et al. Highly predictive survival nomogram after upper urinary tract urothelial carcinoma. Cancer. 2010;116(16):3774-3784. doi:10.1002/cncr.25122

12. Ball RY. Pathology and genetics of tumours of the urinary system and male genital organs. Histopathology. 2005;46(5):586. doi:10.1111/ j.1365-2559.2005.02096.x

13. Cuccurullo V, Mansi L. AJCC cancer staging handbook: from the AJCC cancer staging manual (7th edition). Eur J Nucl Med Mol Imaging. 2011;38(2):408. doi:10.1007/s00259-010-1693-9

14. Fuhrman SA, Lasky LC, Limas C. Prognostic significance of morphologic parameters in renal cell carcinoma. Am J Surg Pathol. 1982;6(7):655-663. doi:10.1097/00000478-198210000-00007

15. Harrell FE, Lee KL, Mark DB. Multivariable prognostic models: issues in developing models, evaluating assumptions and adequacy, and measuring and reducing errors. Stat Med. 1996;15(4):361-387. doi:10.1002/(SICI)1097-0258(19960229)15:4<361::AID-SIM168>3. $0 . \mathrm{CO} ; 2-4$

16. Harrell FE, Califf RM, Pryor DB, et al. Evaluating the yield of medical tests. JAMA. 1982;247(18):2543-2546. doi:10.1001/ jama.1982.03320430047030

17. Sejima T, Iwamoto H, Masago T, et al. Oncological and functional outcomes after radical nephrectomy for renal cell carcinoma: a comprehensive analysis of prognostic factors. Int J Urol. 2013;20 (4):382-389. doi:10.1111/j.1442-2042.2012.03176.x

18. Zhao H, Cao Y, Wang Y, et al. Dynamic prognostic model for kidney renal clear cell carcinoma (KIRC) patients by combining clinical and genetic information. Sci Rep. 2018;8(1):17613. doi:10.1038/s41598018-35981-5
19. Yaycioglu O, Eskicorapci S, Karabulut E, et al. A preoperative prognostic model predicting recurrence-free survival for patients with kidney cancer. Jpn J Clin Oncol. 2013;43(1):63-68. doi:10.1093/ jjco/hys 192

20. Karakiewicz PI, Suardi N, Capitanio U, et al. A preoperative prognostic model for patients treated with nephrectomy for renal cell carcinoma. Eur Urol. 2009;55(2):287-295. doi:10.1016/j.eururo.20 08.07.037

21. Bandini M, Smith A, Zaffuto E, et al. Effect of pathological high-risk features on cancer-specific mortality in non-metastatic clear cell renal cell carcinoma: a tool for optimizing patient selection for adjuvant therapy. World J Urol. 2018;36(1):51-57. doi:10.1007/s00345-017-2093-6

22. Marchioni M, Bandini M, Pompe RS, et al. The impact of lymph node dissection and positive lymph nodes on cancer-specific mortality in contemporary $\mathrm{pT}$ non-metastatic renal cell carcinoma treated with radical nephrectomy. BJU Int. 2018;121(3):383-392. doi:10.1111/bju.14024

23. Raj GV, Thompson RH, Leibovich BC, et al. Preoperative nomogram predicting 12-year probability of metastatic renal cancer. J Urol. 2008;179 (6):2146-2151; discussion 2151. doi:10.1016/j.juro.2008.01.101

24. Yang H, Yin K, Wang Y, et al. Pre-existing type 2 diabetes is an adverse prognostic factor in patients with renal cell carcinoma. J Diabetes. 2019;11(12):993-1001. doi:10.1111/1753-0407.12957

25. Djiogue S, Nwabo Kamdje AH, Vecchio L, et al. Insulin resistance and cancer: the role of insulin and IGFs. Endocr Relat Cancer. 2013;20(1):R1-R17. doi:10.1530/ERC-12-0324

26. Haase VH. The VHL/HIF oxygen-sensing pathway and its relevance to kidney disease. Kidney Int. 2006;69(8):1302-1307. doi:10.1038/sj. ki.5000221

27. Buti S. A new prognostic model for localized renal cell carcinoma. World J Urol. 2019;37(1):211-212. doi:10.1007/s00345-018-2335-2

28. Buti S, Puligandla M, Bersanelli M, et al. Validation of a new prognostic model to easily predict outcome in renal cell carcinoma: the GRANT score applied to the ASSURE trial population. Ann Oncol. 2017;28(11):2747-2753. doi:10.1093/annonc/mdx492

29. May M, Brookman-Amissah S, Kendel F, et al. Validation of a postoperative prognostic model consisting of tumor microvascular invasion, size, and grade to predict disease-free and cancer-specific survival of patients with surgically resected renal cell carcinoma. Int J Urol. 2009;16 (7):616-621. doi:10.1111/j.1442-2042.2009.02319.x

30. Cindolo L, Chiodini P, Gallo C, et al. Validation by calibration of the UCLA integrated staging system prognostic model for nonmetastatic renal cell carcinoma after nephrectomy. Cancer. 2008;113(1):65-71. doi:10.1002/cner.23517

31. Terrone C, Volpe A. The role of pathology for clinical decision-making in renal cell carcinoma is increasing. Eur Urol. 2007;51(5):1166-1168; discussion 1168-1170. doi:10.1016/j. eururo.2007.01.018

32. Frank I, Blute ML, Cheville JC, et al. A multifactorial postoperative surveillance model for patients with surgically treated clear cell renal cell carcinoma. J Urol. 2003;170:2225-2232. doi:10.1097/01. ju.0000095541.10333.a7

33. Frank I, Blute ML, Cheville JC, et al. An outcome prediction model for patients with clear cell renal cell carcinoma treated with radical nephrectomy based on tumor stage, size, grade and necrosis: the SSIGN score. J Urol. 2002;168(6):2395-2400. doi:10.1016/S00225347(05)64153-5

34. Zisman A, Pantuck AJ, Wieder J, et al. Risk group assessment and clinical outcome algorithm to predict the natural history of patients with surgically resected renal cell carcinoma. J Clin Oncol. 2002;20 (23):4559-4566. doi:10.1200/JCO.2002.05.111

35. Han KR, Bleumer I, Pantuck AJ, et al. Validation of an integrated staging system toward improved prognostication of patients with localized renal cell carcinoma in an international population. $J$ Urol. 2003;170:2221-2224. doi:10.1097/01.ju.0000096049.64863.a1 
36. Zhu Y, Zhao YR, Yang XF, et al. Postoperative prognostic model for patients with clear cell renal cell carcinoma in a Chinese population. Int J Urol. 2019;26(6):624-629. doi:10.1111/iju.13936

37. Buti S, Karakiewicz PI, Bersanelli M, et al. Author Correction: Validation of the GRade, Age, Nodes and Tumor (GRANT) score within the Surveillance Epidemiology and End Results (SEER) database: a new tool to predict survival in surgically treated renal cell carcinoma patients. Sci Rep. 2020;10(1):2304. doi:10.1038/s41598-020-59358-9

38. Buti S, Karakiewicz PI, Bersanelli M, et al. Validation of the GRade, Age, Nodes and Tumor (GRANT) score within the Surveillance Epidemiology and End Results (SEER) database: a new tool to predict survival in surgically treated renal cell carcinoma patients. Sci Rep. 2019;9(1):13218. doi:10.1038/s41598-019-49250-6

39. Bandini M, Smith A, Marchioni M, et al. Adjuvant therapies in nonmetastatic renal-cell carcinoma: a review of the literature. Clin Genitourin Cancer. 2018;16(3):176-183. doi:10.1016/j.clgc.2018.01.003
40. Ravaud A, Motzer RJ, Pandha HS, et al. Adjuvant sunitinib in high-risk renal-cell carcinoma after nephrectomy. $N$ Engl J Med. 2016;375(23):2246-2254. doi:10.1056/NEJMoa1611406

41. Bex A, Albiges L, Ljungberg B, et al. Updated European Association of Urology guidelines for cytoreductive nephrectomy in patients with synchronous metastatic clear-cell renal cell carcinoma. Eur Urol. 2018;74(6):805-809. doi:10.1016/j.eururo.2018.08.008

42. Karakiewicz PI, Zaffuto E, Kapoor A, et al. Kidney Cancer Research Network of Canada consensus statement on the role of adjuvant therapy after nephrectomy for high-risk, non-metastatic renal cell carcinoma: a comprehensive analysis of the literature and meta-analysis of randomized controlled trials. Can Urol Assoc J. 2018;12(6):173-180. doi:10.5489/cuaj.5187

\section{Publish your work in this journal}

Cancer Management and Research is an international, peer-reviewed open access journal focusing on cancer research and the optimal use of preventative and integrated treatment interventions to achieve improved outcomes, enhanced survival and quality of life for the cancer patient.
The manuscript management system is completely online and includes a very quick and fair peer-review system, which is all easy to use. Visit http://www.dovepress.com/testimonials.php to read real quotes from published authors. 